\title{
AS RECENTES POLÍTICAS PÚBLICAS DE AUTOCOMPOSIÇÃO DE CONFLITOS E A (IN)COMPATÍVEL FORMAÇÃO DOS PROFISSIONAIS DE DIREITO
}

\author{
http://dx.doi.org/10.21527/2176-6622.2021.55.49-57
}

Recebido em: 19/2/2020

Aceito em: 20/4/2020

Camila Stangherlin

Autora correspondente. Universidade de Santa Cruz do Sul (Unisc). Av. Independência, 2293 - Universitário. CEP 96816-501. Santa Cruz do Sul/RS, Brasil. http://lattes.cnpq.br/6684390089442616. https://orcid.org/0000-0001-8689-1358. camilastangherlin@hotmail.com

Fabiana Marion Spengler

Universidade de Santa Cruz do Sul (Unisc). Santa Cruz do Sul/RS, Brasil.

\section{RESUMO}

Nos últimos anos, o Brasil instituiu uma política pública voltada à efetivação do direito de acesso à justiça por meio de mecanismos autocompositivos, o que fora alicerçado na edição de normas resolutivas. Nesse aspecto, os cursos de Direito receberam orientações para um ajustamento em conformidade com essas definições. A presente pesquisa objetiva compreender o panorama atual de formação básica de profissionais de Direito, essencialmente no que diz respeito à sua preparação para as práticas de resolução de conflitos pautadas em autonomia, diálogo e consensualidade entre os envolvidos. O método de abordagem é o dedutivo e o levantamento de dados se deu por fontes primárias e secundárias (pesquisa documental e pesquisa bibliográfica). 0 problema que move o trabalho questiona: As diretrizes da formação jurídica fundamental encontram-se alinhadas às disposições presentes nas resoluções que contemplam as atividades autocompositivas? A conclusão aponta para uma formação ainda incipiente naquilo que se refere ao estudo e à capacitação para formas consensuais de resolução de conflitos.

Palavras-chave: Autocomposição. Conflito. Ensino jurídico. Políticas públicas. Profissionais jurídicos.

\section{RECENT PUBLIC POLICIES FOR CONFLICT SELF-COMPOSITION AND THE (IN) COMPATIBLE TRAINING OF LAW PROFESSIONALS}

\section{ABSTRACT}

In recent years, Brazil has instituted a public policy aimed at the realization of the right of access to justice through self-composition mechanisms, which was based on the edition of resolutive norms. In this regard, the law courses received guidelines for adjustment in accordance with these implementations. This research aims to understand the current panorama of basic training of law professionals, essentially, regarding their preparation for conflict resolution practices based on autonomy, dialogue and consensus among those involved. The approach method is deductive and the data collection was done by primary and secondary sources (documentary research and bibliographic research). The problem that moves the work asks: are the guidelines of fundamental legal training aligned with the provisions present in the resolutions that contemplate self-composing activities? The conclusion points to a training that is still incipient in what concerns the study and training for consensual forms of conflict resolution.

Keywords: Self-composition. Conflict. Legal education. Public policy. Legal professionals.

\section{SUMÁRIO}

1 Introdução. 2 Política pública de acesso à justiça: as recentes políticas judiciárias criadas no país e suas especificidades. 3 A resolução no 125/2010 do Conselho Nacional de Justiça e seus reflexos no ensino jurídico. 4 A formação jurídica básica e suas atuais perspectivas no contexto autocompositivo. 5 Conclusão. 6 Referências. 


\section{INTRODUÇÃO}

O direito fundamental de acesso à justiça, insculpido no artigo 5o, inciso XXXV, da Constituição Federal de 1988, não pode ser sinônimo de acesso ao Judiciário. Trata-se de um direito mais amplo, abarcado na qualidade da prestação dos serviços jurídicos e na satisfação do jurisdicionado com a resposta obtida para sua demanda. Para tanto, sabe-se que nem sempre a decisão impositiva (decisão adjudicada) tem o condão de dar à lide um desfecho que favoreça os interesses dos envolvidos, assim como, na maioria das vezes, não propicia a pacificação das relações sociais - um dos objetivos da jurisdição.

Sendo assim, a política pública de acesso à justiça fora instituída visando a disponibilizar aos cidadãos práticas que fomentem a disseminação da cultura pacifista. Mediante a conciliação e a mediação, os conflitantes, com o auxílio de um terceiro imparcial, possuem a oportunidade de participação ativa na construção de uma solução que, conjuntamente, elegem justa. A política, que nasceu ampla, foi, pouco a pouco, recebendo manejo específico de alguns segmentos do Poder Judiciário, como na seara criminal, por meio da Justiça Restaurativa, e na seara trabalhista, com a Política Judiciária de tratamento adequado das disputas de interesses no âmbito da Justiça do Trabalho.

A fim de alcançar concretude, no entanto, faz-se necessário que os profissionais jurídicos - sujeitos responsáveis por interligar cidadão e justiça estatal - obtenham aporte no ensino básico da profissão por meio de uma preparação que não privilegie apenas a convencional litigância assentada em procedimentos contenciosos, mas que, igualmente, oferte o aprendizado de formas que se fundam na justiça consensual.

Destarte, o presente trabalho tem por objetivo compreender o panorama atual de formação de profissionais de Direito, essencialmente no que se refere à sua preparação para práticas de resolução de conflitos pautadas em autonomia, diálogo e consensualidade entre os envolvidos. Quanto à metodologia adotada, o método de abordagem é o dedutivo, e o levantamento de dados se dará por intermédio de fontes primárias e secundárias (pesquisa documental e pesquisa bibliográfica). Nesse sentido, o problema que move o trabalho questiona: As diretrizes da formação jurídica fundamental encontram-se alinhadas às disposições presentes nas resoluções que contemplam as atividades autocompositivas?

A hipótese levantada aponta para uma resposta afirmativa, uma vez que, existindo norma jurídica disciplinado o assunto, torna-se arrazoada a presença de ações que concedam sentido ao que fora preestabelecido, dando azo à consubstanciação do tema.

Primeiramente, irá ser estudada, de forma geral, a instauração da política pública de acesso à justiça por meio da Resolução no 125/2010 do Conselho Nacional de Justiça - CNJ -, e as posteriores políticas judiciárias nacionais que foram estabelecidas pela Resolução no 225/2016, também do CNJ, e Resolução no 174/2016, do Conselho Superior da Justiça do Trabalho - CSJT. Por conseguinte, será abordada a Resolução no 125/2010 a partir de suas designações para com os profissionais atuantes em mecanismo de solução pacífica de conflitos, sob o panorama das instituições da área de ensino (bacharelado em Direito) e suas responsabilidades.

Por fim, serão averiguadas as diretrizes atuais que tratam sobre o enfoque da autocomposição de conflitos no âmbito da formação jurídica, a fim de analisar sua adequação às perspectivas suscitadas pela política pública de acesso à justiça qualitativa. Para isso, será levada em consideração a normativa proveniente do órgão público incumbido de formular e avaliar a política nacional de educação no Ensino Superior.

\section{POLÍTICA PÚBLICA DE ACESSO À JUSTIÇA: AS RECENTES POLÍTICAS JUDICIÁRIAS CRIADAS NO PAÍS E SUAS ESPECIFICIDADES}

Falar em Poder Judiciário é discorrer sobre o monopólio da jurisdição, uma vez que essa é uma de suas principais características. Esse escopo jurídico, todavia, centralizado na imposição de soluções às disputas de interesse, foi se mostrando insuficiente e/ou inadequado ao perfil altamente complexo das relações sociais vislumbradas nos últimos anos.

Diante de um cenário de elevada litigiosidade, o direito fundamental de acesso à justiça vinha sendo rechaçado ante a um Poder Judiciário que não se atentava aos óbices diários presentes nos tribunais, como a morosidade, altos custos ao cidadão, formalismo excessivo, carência de informações, entre outros - o que os autores Mauro Cappelletti e Bryant Garth identificaram como “barreiras ao acesso" (1988, p. 29). 
Encontrar formas de superar tais obstáculos é um desafio constante. Na visão de Rodolfo de Camargo Mancuso, uma saída possível de um impasse nesses moldes, com fulcro na satisfação da sociedade com as respostas/serviços assegurados pelo Poder Judiciário, está em uma conjugação de fatores:

um de caráter social, a saber, a superação da mentalidade demandista e da cultura judiciarista, com o fomento de outros meios, auto e heterocompositivos; outro ligado à vontade política, consistente na produção de leis processuais progressistas e inovadoras, acompanhadas dos devidos investimentos em estrutura e logística (MANCUSO, 2014, p. 342).

Ao Estado, para dar efetividade aos ditames do direito de acesso à justiça provenientes da CF/88, cabe identificar e neutralizar essa gama de entraves por meio de programas, ações e atividades específicas traduzidas em políticas públicas. Nesse sentido, a conscientização a respeito da necessidade de se estabelecer uma política pública que atendesse aos problemas identificados, começou a tomar forma perante as inquietações produzidas por diversos movimentos (de profissionais jurídicos, do meio acadêmico, de grupos de estudo/ pesquisa, de profissionais de outras áreas, entre outros).

Nesse contexto, é editada a Resolução no 125/2010 do Conselho Nacional de Justiça - CNJ. Sob a "necessidade de consolidar política pública permanente de incentivo e aperfeiçoamento dos mecanismos consensuais de solução de litígios" (CONSELHO NACIONAL DE JUSTIÇA, 2010), a Política Judiciária Nacional de tratamento adequado dos conflitos de interesses no âmbito do Poder Judiciário, irrompe-se como um verdadeiro divisor de águas, introduzindo práticas como a mediação e a conciliação na realidade dos tribunais.

Ademais, a ressignificação do direito de acesso à justiça passou a ser debatida. Pode-se afirmar que, por meio da Resolução no 125/CNJ, houve um investimento por parte do Estado em uma política pública forte, visando a impulsionar, sobretudo, os meios autocompositivos. No revés de submeterem seus conflitos ao Judiciário, "as partes passam a interagir com o estabelecimento de diálogo, auxiliadas por um conciliador ou mediador na busca de um consenso. Interagem e se engajam no processo de forma dialética, reconhecendo os limites de seus direitos comuns e recíprocos" (AQUINO, 2017, p. 225). Desse modo, como uma política pública permanente de incentivo e aperfeiçoamento dos mecanismos consensuais de solução de litígios, a Política Judiciária Nacional de tratamento dos conflitos de interesses produziu reflexos.

O Conselho Superior da Justiça do Trabalho - CSJT -, tendo por fundamento o conteúdo da Resolução no 125/2010 (assim como material reunido e discutido conjuntamente por determinado grupo de estudos), disciplinou o tema da autocomposição judicial a partir da edição da Resolução no 174, de 30 de setembro de 2016, tratando, precisamente, da política judiciária nacional de tratamento adequado das disputas de interesses no âmbito do Poder Judiciário Trabalhista, e dando outras providências.

A inserção de mecanismos de justiça consensual nas relações conflitivas do campo trabalhista, aos moldes da mediação e da conciliação, teve de percorrer um caminho mais longo se comparado com a institucionalização dessas práticas no cenário da Justiça Comum. Observou-se uma resistência muito acentuada, sobretudo com posicionamentos que defendem que "normas trabalhistas trazem direitos indisponíveis para o seu titular, por possuírem condão alimentar" (SPENGLER, 2017, p. 114).

Dessa forma, arraigada fortemente na segurança jurídica, priorizou-se a mantença de profissionais da área (magistrados e servidores inativos), já adaptados ao sistema procedimental da jurisdição convencional, para desempenhar a função de mediador. Esse é um aspecto que merece grande atenção, uma vez que se tem no juiz o perfil de um profissional "concursado para decidir e sentenciar" (SPENGLER, 2017, p. 129).

Na visão de Gutiérrez e Magalhães (2019, p. 176), há um "engessamento regulatório - promovido pelo principal órgão da Justiça do Trabalho brasileira - dos métodos consensuais, não permitindo o desenvolvimento orgânico desses". A excessiva atenção aos preceitos que mantêm o desenvolvimento de meios autocompositivos sob a égide da segurança jurídica, acaba contribuindo para uma minoração da autonomia dos conflitantes, que encontram no conciliador/mediador o simbolismo próprio do Poder Judiciário.

Na verdade, a Resolução no 174/2016 mostra-se como uma ação decorrente da política pública principiada pelo CNJ, em 2010, amparada na ideia central de reformulação das vias da tradicional jurisdição (em muito, fomentada, também, pelas práticas que demonstravam o êxito das soluções extrajudiciais). A tradução dessa concepção inicial, todavia, mostrou-se avessa: sem abandonar o caráter hierárquico, típico da atividade 
estatal de dizer o direito, o representante do Estado foi mantido ao centro, ainda que se fale em autocomposição. Daí a fundamentalidade de uma capacitação basilar que prepare todo e qualquer profissional jurídico para as práticas de uma justiça consensual.

Outro segmento do Poder Judiciário que buscou regulamentar os mecanismos propagadores de uma ordem jurídica justa, foi a seara criminal.

Com cerne no direito fundamental de acesso à justiça e na concretização de meios que propiciem a solução efetiva de conflitos por intermédio de mecanismos consensuais voluntários, a Resolução $n^{\circ} 225$, de 31 de maio de 2016, do Conselho Nacional de Justiça, estabeleceu a política nacional de justiça restaurativa no âmbito do Poder Judiciário. Consubstanciada nas recomendações proferidas pela Organização das Nações Unidas $(\mathrm{ONU})^{1}$, o CNJ instituiu a previsão de procedimentos de cunho reparatório, tendo por base a inter-relação do tripé vítima, ofensor e comunidade.

Nessa esteira, o conflito recebe uma conotação diferenciada: passa a estar associado à prática da violência, passa a trazer consigo vítimas. A partir do estabelecimento de um processo dialógico, intenta-se a substituição ao tradicional modelo punitivo, centrado na retribuição, por meio de uma proposta abarcada no restabelecimento daquilo que fora lesado.

É bem verdade que nem sempre o reparo estará ao alcance dos limites e das possibilidades dos envolvidos, contudo, ainda assim, o caminho para a efetivação da justiça tem aporte nos passos iniciais, propiciados pela proposta restauradora. Para melhor compreensão acerca do conceito de justiça restaurativa, é pertinente a reflexão de Howard Zehr ao tratar sobre a mudança paradigmática envolvendo a temática crime e justiça:

Quando um mal é cometido, a questão central não deveria ser "o que devemos fazer ao ofensor?", ou "o que o ofensor merece?", mas sim "o que devemos fazer para corrigir a situação?" Em vez de definir a justiça como retribuição, nós a definiremos como restauração. Se o crime é um ato lesivo, a justiça significará reparar a lesão e promover a cura. Atos de restauração - ao invés de mais violação - deveriam contrabalançar o dano advindo do crime $(2008$, p. 175$)$.

Quanto ao dano, insta destacar que a política nacional judiciária se atentou em prever uma conotação mais ampla, não restringindo os reflexos danosos apenas ao campo material/financeiro, mas também ao âmbito abstrato (que pode englobar vertentes psicológicas, culturais, sentimentais ou simbólicas, por exemplo). De tal sorte, é essencial a instauração de uma atmosfera que coadune com tal finalidade, e que tenha o condão de recepcionar cada participante com fulcro nos pressupostos para a realização de um procedimento restaurativo satisfatório.

Assim, em termos de melhorias na destinação de espaços jurídicos para a efetuação de métodos autocompositivos, menos formais e mais acessíveis ao cidadão, percebe-se que a política pública de acesso à justiça proporcionou inciativas em outros segmentos, com louváveis inovações na estrutura normativa. Perceber, todavia, a insuficiência de previsões normativas desconexas de uma mudança sincrônica, capaz de atingir o conjunto articulado que movimenta o sistema Judiciário, é fundamental para alcançar o aprimoramento. Do mesmo modo,

A reforma a que se almeja no anseio de democratização do Estado perpassa, inclusive, pelos refúgios do Poder Judiciário. Torná-lo mais humano e adequado às demandas que se irrompem cotidianamente em nada compatibiliza com a remodelagem de formas satisfatórias em condições diferenciadas e que, conforme absorvidas, recebem os moldes próprios da jurisdição contenciosa (STANGHERLIN; SPENGLER, 2019, p. 178).

Entrementes, a qualidade na prestação de serviços que abarcam essa totalidade de novos componentes (como os autocompositivos), depende da aceitação dos profissionais jurídicos em tomar para si parte dessa responsabilização. As alterações de ordem legal e/ou administrativa, em que pese representem parte considerável nessa ressignificação da atividade jurisdicional contemporânea, por si só não produzem o efeito prenunciado.

\footnotetext{
A ONU recomendou aos seus estados-membros a criação de canais voltados à justiça restaurativa. Por meio das Resoluções $1999 / 26$, 2000/14 e 2002/12, orientou a adoção de programas que possibilitem o alcance de objetivos restaurativos em matéria criminal, capazes de promover a harmonia social associando vítimas, ofensores e comunidade.
} 
No contexto da ampla política pública constituída, tal como expressam André Leonardo Copetti Santos e José Luis Bolzan de Morais (2007, p. 69), “o Direito passa a ter um caráter transformador da realidade e privilegiar como seu agente não mais, ou apenas, os indivíduos, mas grupos, coletividades, multidões [...]", e, para tanto, é crucial atentar-se ao processo formativo aplicado ao Direito que, na maior parte do tempo, funda-se no tratamento de pretensões de cunho individual. O próximo tópico desenvolverá a abordagem de tal tema.

\section{A RESOLUÇÃO № 125/2010 DO CONSELHO NACIONAL DE JUSTIÇA E SEUS REFLEXOS NO ENSINO JURÍDICO}

De forma geral, as políticas públicas de autocomposição de conflitos têm apresentado variantes que percebem a capacitação dos sujeitos intermediadores como quesito essencial. A Resolução no 125/2010 fala na adequada formação e treinamento não só de conciliadores e mediadores, mas também dos servidores, "com vista à boa qualidade dos serviços" (artigo 2ㅇ). Por sua vez, a Resolução no 225/2016 afirma ser possível o exercício da função de facilitador restaurativo por "servidor do tribunal, agente público, voluntário ou indicado por entidades parceiras", desde que estes estejam capacitados em técnicas autocompositivas e consensuais de solução de conflitos próprias da Justiça Restaurativa (artigo 1으, inc. II).

Já a Resolução no 174/CSJT, diferentemente das demais, assinala de imediato a quem a autocomposição estará vinculada. O magistrado é a terceira pessoa que exercerá o papel de apaziguador do conflito, e, quando não atuar diretamente nessa função, supervisionará o servidor público que estiver em atividade. Dessa forma, a capacitação para as práticas consensuais também foi prevista visando a atender a esses profissionais. Similar ao disposto na Resolução no 125/2010, o artigo 3o, inciso II, da Política Judiciária Nacional de tratamento das disputas de interesses trabalhistas, estipula, "com vistas à boa qualidade destes serviços", a realização, por magistrados e servidores, de uma adequada formação e treinamento para exercer a conciliação e a mediação, podendo, inclusive, ser firmadas parcerias com entidades públicas e privadas.

Ressalvadas as peculiaridades de cada normativa, verifica-se uma atenção, presente nas políticas judiciárias nacionais, referente ao preparo dos sujeitos responsáveis por dar executividade às práticas autocompositivas (não somente os terceiros facilitadores, como já citado, mas os servidores de maneira geral, sublinhando a mudança paradigmática). Tem-se, nesse reconhecimento, um pilar de fixação da política pública com a excelência na prestação dessa novel modalidade de serviços jurídicos, o que está umbilicalmente ligado ao acesso à justiça qualitativa. Na verdade, conforme preceitua Boaventura de Sousa Santos, "o pressuposto é que se não houver uma formação específica, a lei obviamente não será bem aplicada" $(2015$, p. 100).

Avançando um pouco mais, porém, percebe-se que não se trata unicamente de uma capacitação focada na correta aplicação dos ditames normativos (embora muito importantes, inclusive naquilo que aborda a postura ética de mediadores e conciliadores, por exemplo). Mais do que isso, a formação adequada perpassa pela noção da relação dialógica existente entre o cumprimento das orientações contidas na norma e a função social por trás da política pública.

Nesse aspecto, os cursos que se voltam à constituição de profissionais aptos a esse universo (tanto os cursos de Bacharelado em Direito quanto os cursos preparatórios específicos apontados pelas resoluções) não podem se mostrar herméticos às tendências humanistas, interdisciplinares e de abrangência plural. $O$ vínculo entre Estado e sociedade já não é o mesmo de outrora, e a interação do direito com os conflitos sociais precisa acompanhar essa evolução por meio de sujeitos munidos de um saber homólogo.

Além do mais, como afirma Fabiana Marion Spengler (2017, p. 69), "a política pública que institui a mediação e a conciliação como meios alternativos de tratamento de conflitos, [...] pretende, entre outras coisas, construir outra mentalidade junto aos juristas brasileiros", o que aponta um comprometimento amplo, que ultrapassa a barreira dos resultados imediatos (problemas aparentes), adentrando o campo da percepção cultural de um povo.

Um dos pontos centrais que frisa essa atividade responsiva a ser efetivada pelas instituições de ensino, consta no artigo 60 da Resolução no 125/CNJ. A política judiciária elegeu como sendo atribuição do Conselho Nacional de Justiça "buscar a cooperação dos órgãos públicos competentes e das instituições públicas e privadas da área de ensino, para a criação de disciplinas que propiciem o surgimento da cultura da solução pacífica dos conflitos" (CONSELHO NACIONAL DE JUSTIÇA, 2010). 
Passada uma década desde a entrada em vigor da resolução, tem-se ganhos notáveis sobre esse aspecto que merecem análise. O próximo item irá averiguar, de modo geral, as principais concretizações no ensino jurídico a respeito da edificação de uma cultura pacifista dentre os profissionais de Direito em formação.

\section{A FORMAÇÃO JURÍDICA BÁSICA E SUAS ATUAIS PERSPECTIVAS NO CONTEXTO AUTOCOMPOSITIVO}

A formação acadêmica dos bacharéis em Direito criou raízes profundas, e há quase dois séculos se tem priorizado no país o estudo jurídico nos moldes do conservadorismo. Ademais, a crescente mercantilização do ensino desencadeou a disseminação de diversos cursos de Direito comprometidos, demasiadamente, com o faturamento em detrimento da qualidade da formação profissional de seus discentes. O viés pedagógico, científico e humanístico por muito tempo viu-se rechaçado, de maneira que o Direito se engendrou como ciência estática e como fenômeno social apartado do contexto dinâmico da sociedade. Tornou-se refém das normativas positivadas em códigos e, assim, esquivou-se da reestruturação requerida pela nova faceta dos conflitos sociais.

Como se a complexidade fosse efêmera, o Direito insistiu em seu posicionamento inerte e deu segmento à formação de verdadeiros "técnicos jurídicos", habilitados em cumprir a letra da lei. Nesse ínterim, "a complexidade não desaparece! Ela cresce e continuará crescendo, pois todos se aproveitam do conforto e da liberdade que vem embutida; ela caracteriza a democracia (SERRES, 2018, p. 82)". Oportunizar respostas adequadas aos distintos conflitos que adentram a órbita jurídica é função do Estado, como garantidor de um acesso à justiça qualitativo aos seus cidadãos.

Sob tal viés, e a fim de dar efetividade aos preceitos da política pública inaugurada pela Resolução no $125 / 2010$ do CNJ, as instituições de ensino logo viram a necessidade de adaptação a essa nova conjuntura. No intuito de ajustar as diretrizes dos cursos de Graduação em Direito às propostas de incentivo aos mecanismos consensuais, fora editada a Resolução CNE/CES no 5, de 18 de dezembro de 2018. ${ }^{2}$

Nesse aspecto, convém destacar que o Ministério da Educação - MEC (órgão da administração federal direta que tem como área de competência a política nacional de educação) - é responsável por elaborar as diretrizes curriculares nacionais básicas norteadoras dos cursos de Graduação, estabelecendo uma composição organizacional comum a todos que estão inseridos no ensino jurídico. Por seu turno, cabe ao Conselho Nacional de Educação - CNE -, e suas respectivas Câmaras (sendo a Câmara de Educação Superior - CES - uma delas), assegurar a participação da sociedade no desenvolvimento, aprimoramento e consolidação da educação nacional de qualidade.

Assim, a Resolução CNE/CES no 5 acrescentou no rol de conteúdos necessários para a formação técnico-jurídica do bacharel em Direito, o estudo das formas consensuais de solução de conflitos, tal como preconizado pela Resolução 125/CNJ. Um significativo avanço para o campo das disciplinas que, comumente, figuravam na lista de eletivas/optativas, e, eventualmente, restavam desacompanhadas de um viés pedagógico capaz de instituir uma reconstrução da tradicional visão do bacharelando.

Ainda, introduziu, no decorrer do seu texto, expressões atinentes à diversidade sociocultural, à interdisciplinaridade, ao pluralismo contemporâneo e à importante preparação acadêmica para a solução de conflitos arrimada no diálogo e na autonomia dos envolvidos, como pode ser constatado a seguir:

Art. 30 curso de graduação em Direito deverá assegurar, no perfil do graduando, sólida formação geral, humanística, capacidade de análise, domínio de conceitos e da terminologia jurídica, capacidade de argumentação, interpretação e valorização dos fenômenos jurídicos e sociais, além do domínio das formas consensuais de

\footnotetext{
De acordo com o artigo 1ํ, o conteúdo da Resolução CNE/CES no 5 "institui as Diretrizes Curriculares Nacionais do curso de graduação em Direito, bacharelado, a serem observadas pelas Instituições de Educação Superior (IES)". Trata-se de documento assinado por Antonio de Araújo Freitas Júnior, presidente da Câmara de Educação Superior do Conselho Nacional de Educação, no uso de suas atribuições legais, com fundamento no artigo 9o, § 2으, alínea "e", da Lei no 4.024, de 20 de dezembro de 1961, com a redação dada pela Lei no 9.131 , de 25 de novembro de 1995, e as Diretrizes Curriculares Nacionais elaboradas pela Câmara Consultiva Temática de Política Regulatória do Ensino Jurídico, propostas ao CNE pela Secretaria de Regulação e Supervisão da Educação Superior do Ministério da Educação (Seres/MEC), e com fundamento no Parecer CNE/CES no 635/2018, homologado pela Portaria MEC no 1.351, de 14 de dezembro de 2018.
} 
composição de conflitos, aliado a uma postura reflexiva e de visão crítica que fomente a capacidade e a aptidão para a aprendizagem, autônoma e dinâmica, indispensável ao exercício do Direito, à prestação da justiça e ao desenvolvimento da cidadania.

Na mesma compreensão, o artigo 4ㅇe enfatiza a essencialidade de posturas educativas que possibilitem o ensino e a aprendizagem também imergidos na área interpessoal (e não estritamente na área cognitiva), sendo essa propulsora de uma cultura pacifista:

Art. 4ㅇ O curso de graduação em Direito deverá possibilitar a formação profissional que revele, pelo menos, as competências cognitivas, instrumentais e interpessoais, que capacitem o graduando a:

$[\ldots]$

$\mathrm{VI}$ - desenvolver a cultura do diálogo e o uso de meios consensuais de solução de conflitos;

Complementando, o artigo 5o frisa o teor de obrigatoriedade atrelado às disciplinas autocompositivas, de maneira que os Projetos Pedagógicos dos cursos de Direito devem adequar seus conteúdos de forma a incluir o ensino que abarque as formas consensuais de solução de conflitos.

Art. 5o $\mathrm{O}$ curso de graduação em Direito, priorizando a interdisciplinaridade e a articulação de saberes, deverá incluir no PPC, conteúdos e atividades que atendam às seguintes perspectivas formativas:

$[\ldots]$

II - Formação técnico-jurídica, que abrange, além do enfoque dogmático, o conhecimento e a aplicação, observadas as peculiaridades dos diversos ramos do Direito, de qualquer natureza, estudados sistematicamente e contextualizados segundo a sua evolução e aplicação às mudanças sociais, econômicas, políticas e culturais do Brasil e suas relações internacionais, incluindo-se, necessariamente, dentre outros condizentes com o PPC, conteúdos essenciais referentes às áreas de Teoria do Direito, Direito Constitucional, Direito Administrativo, Direito Tributário, Direito Penal, Direito Civil, Direito Empresarial, Direito do Trabalho, Direito Internacional, Direito Processual; Direito Previdenciário, Formas Consensuais de Solução de Conflitos.

Importa destacar, ainda, que o artigo 14 estabelece o prazo para efetivação das orientações apresentadas pela resolução, determinando que as Diretrizes Curriculares Nacionais deverão ser introduzidas pelas IESs, obrigatoriamente, no prazo máximo de até dois anos aos alunos ingressantes, a partir da sua data de publicação.

A edição de um ato normativo indicando a necessidade de uma formação menos focada em procedimentos contenciosos, reflete as conquistas de uma discussão iniciada há largos anos, que enxergava na alteração/ajustamento das matrizes curriculares jurídicas, condição indispensável para uma mudança cultural: em prol de uma sociedade mais pacífica e com menores índices de judicialização de conflitos. Por óbvio, não se pode crer que o teor resolutivo seja suficiente para construir tal transição.

Para tanto, além de uma reestruturação no conteúdo mínimo de formação jurídica - em consonância com a política judiciária nacional - torna-se essencial atentar-se às influências e desenvolvimentos pedagógicos que conduzem professores e alunos nas salas de aula. Como afirma Morin (2004, p. 105), "qualquer concepção do gênero humano significa desenvolvimento conjunto das autonomias individuais", associado, ainda, ao sentimento de pertencimento à coletividade. Tais pressupostos não podem ser auferidos tão somente pela aprendizagem tecnicista, mas pela instrumentalidade de uma pedagogia cidadã.

Nesse viés, a complementariedade às coordenadas estabelecidas pelo Conselho Nacional de Educação/ Câmara de Educação Superior requer um olhar atento dentro do campo educativo, com práticas associadas às orientações advindas do conjunto normativo, mas, sobretudo, com posturas que condigam com os preceitos de uma sociedade mais harmônica e menos dependente de decisões judiciais impositivas para a resolução dos conflitos sociais cotidianos. Um aprofundamento, no entanto, na análise da seara educativa para a abordagem dessa proposta pedagógica, anseia por uma pesquisa que priorize tais elementos, o que poderá ser realizado em ocasião futura.

De tal sorte, as perspectivas imanentes à formação básica jurídica no contexto da autocomposição de conflitos demonstram a adoção de passos importantes a serem realizados em um conjunto de ações, norteadas pelo propósito inicial definido pela política pública de acesso à justiça. 


\section{Direito目

\section{CONCLUSÃO}

Na última década, a edição da Resolução no 125/2010, do Conselho Nacional de Justiça - CNJ -, representou uma reação/enfrentamento por parte do Estado aos elevados índices de judicialização dos conflitos sociais, com desdobramentos e previsões que conferiram à Política Judiciária Nacional de tratamento adequado dos conflitos de interesses no âmbito do Poder Judiciário, a condição de percursora de uma série de ações em prol da institucionalização de mecanismos autocompositivos. A Resolução no 225/2016 do CNJ, assim como a Resolução no 174/2016 do Conselho Superior da Justiça do Trabalho - CSJT -, também representaram um avanço em busca de práticas mais dialogadas, consensuais e autônomas, respeitadas as particularidades intrínsecas a cada uma delas.

Nessa contemporânea readequação da estrutura dos serviços jurídicos disponibilizados aos cidadãos, o papel dos profissionais de Direito necessita ser realinhado. Nesse aspecto, a norma jurídica, que disciplinou a política judiciária nacional de resolução pacífica de conflitos, atentou-se em orientar a busca pela cooperação dos órgãos públicos competentes e das instituições públicas e privadas da área de ensino, para a criação de disciplinas que propiciem o surgimento da cultura autocompositiva.

Com a realização da presente pesquisa pode-se concluir que as diretrizes da formação jurídica básica - Bacharelado em Direito - se encontram em visível adaptação às disposições contidas na normativa supracitada. Isso porque, com a edição da Resolução CNE/CES no 5, de 18 de dezembro de 2018, os cursos jurídicos passaram a ser norteados por um rol de conteúdos fundamentais diferenciado, em que o estudo das formas consensuais de solução de conflitos figura como quesito obrigatório.

Salienta-se, contudo que, perante a gama de conteúdos destinada ao preparo de profissionais capacitados para a tradicional disputa judicial, ainda é incipiente a inserção de disciplinas que priorizam a formação humanística, bem como de conteúdos que se ocupam de uma instrução menos beligerante. Os estudantes, quando no cerne da formação jurídica, necessitam de uma compreensão mais profunda acerca do direito de acesso à justiça, para que, então, tornem-se responsáveis pela concretização do teor das normas que tratam sobre uma justiça mais autônoma e consensual.

\section{REFERÊNCIAS}

AQUINO, Maria da Glória Costa Gonçalves de Sousa. Considerações sobre a Resolução CNJ no 125/2010: Uma avaliação política da política judiciária brasileira - a solução dos conflitos de interesses? 1. ed. Rio de Janeiro: Lumen Juris, 2017.

CAPPELLETTI, Mauro; GARTH, Bryant. Acesso à justiça. Tradução Ellen Gracie Northfleet. Porto Alegre: Sergio Antonio Fabris, 1988.

CONSELHO NACIONAL DE EDUCAÇÃO. Resolução CNE/CES 9/2004. Institui as Diretrizes Curriculares Nacionais do Curso de Graduação em Direito e dá outras providências. Disponível em: http://portal.mec.gov.br/cne/arquivos/pdf/rces09_04.pdf. Acesso em: 15 fev. 2020.

CONSELHO NACIONAL DE JUSTIÇA. Resolução 125, de 29 de novembro de 2010. Disponível em: http://www.cnj.jus.br/atos-administrativos/atos-da-presidencia/resolucoespresidencia/12243-resolucao-no-125-de-29-de-novembro-de-2010. Acesso em: 14 fev. 2020.

CONSELHO NACIONAL DE JUSTIÇA. Resolução 225, de 31 de maio de 2016. Disponível em: https://atos.cnj.jus.br/files/resolucao_225_31052016_02062016161414.pdf. Acesso em: 25 jan. 2020.

CONSELHO SUPERIOR DA JUSTIÇA DO TRABALHO. Resolução 174, de 30 de setembro de 2016. Disponível em: http://www. csjt.jus.br/c/document_library/get_file?uuid=235e3400-9476-47a0-8bbb-bccacf94fab4\&groupld=955023. Acesso em: 12 fev. 2020.

GUTIÉRREZ, Daniel Mota; MAGALHÃES, Victor Alves. Acesso à justiça e igualdade: críticas à Resolução no $174 / 2016$ do ConseIho Superior da Justiça do Trabalho. Revista Juris Poiesis, Rio de Janeiro, v. 22, n. 30, p. 168-185, 2019.

MANCUSO, Rodolfo de Camargo. A resolução dos conflitos e a função judicial no contemporâneo Estado de Direito. 2. ed. São Paulo: Revista dos Tribunais, 2014.

MORIN, Edgar. Os sete saberes necessários à educação do futuro. 9. ed. São Paulo: Cortez; Brasília, DF: Unesco, 2004.

SANTOS, André Leonardo Copetti; MORAIS, José Luis Bolzan de. O ensino jurídico e a formação do bacharel em Direito: diretrizes político-pedagógicas do curso de Direito da Unisinos. Porto Alegre: Livraria do Advogado, 2007.

SANTOS, Boaventura de Sousa. Para uma revolução democrática da justiça. Coimbra: Almedina, 2015.

SERRES, Michel. Polegarzinha. Tradução Jorge Bastos. 3. ed. Rio de Janeiro: Bertrand Brasil, 2018. 
SPENGLER, Fabiana Marion. Mediação de conflitos: da teoria à prática. 2. ed. rev. e ampl. Porto Alegre: Livraria do Advogado, 2017.

STANGHERLIN, Camila Silveira; SPENGLER, Fabiana Marion. O poder judiciário e o mito grego do deus Cronos: a judicialização dos meios consensuais de solucionar conflitos e o monopólio de acesso à justiça. Anamorphosis - Revista Internacional de Direito e Literatura, v. 5, n. 1, p. 173-190, 2019.

ZEHR, Howard. Trocando as lentes: um novo foco sobre o crime e a justiça. Tradução Tônia Van Acker. São Paulo: Palas; Athenas, 2008. 